\section{Excess Moisture and Seedcoat Nicking Influence Germination of Triploid Watermelon}

\author{
S.L. Grange ${ }^{1}$ and D.I. Leskovar ${ }^{2}$ \\ Texas Agricultural Experiment Station, Texas A\&M University, Uvalde, \\ TX 78801
}

\section{L.M. Pike}

Vegetable and Fruit Improvement Center, Texas A\&M University Research Park, College Station, TX 77843

\section{B.G. Cobb \\ Department of Horticultural Sciences, Texas A\&M University, College Station, TX 77843}

Additional index words. Citrullus lanatus, ploidy, seedcoat adherence, seedcoat thickness

Abstract. Poor and inconsistent germination is a problem in triploid watermelon. Nicking was shown effective in improving germination in triploid cultivars. In this experiment, we examined the effects of high and low medium moisture, and nicking on diploid and triploid seed germination. Germination for the diploid cultivar was unaffected by any treatment. At high moisture conditions, triploid seed germination was severely reduced to less than $15 \%$, while nicking significantly improved germination up to $40 \%$. However, this increase is still not commercially acceptable. When seed morphological components were measured for each cultivar, triploid seeds had a larger and highly variable air space as compared to the diploid seed. The data confirm that seed germination is not inhibited by the seedcoat alone, but appears to be highly sensitive to excessive water conditions.

Triploid watermelon [Citrullus lanatus (Thunb.) Matsum \& Nakai] consumption has been increasing in the United States. However, poor and inconsistent germination remains a problem. Kihara (1951) noted that like its tetraploid parent, triploid watermelon has a hard and thick seedcoat. This could be a physical barrier to radicle protrusion and a factor resulting in seedcoat adherence to the cotyledons after emergence (Maynard, 1989).

Some research on seedcoat alteration effects on germination of watermelon has been reported. Duval and NeSmith (2000) found that germination of triploid watermelon $\mathrm{cv}$. Genesis was improved when seeds were clipped, with the greatest improvement when the seedcoat was completely removed. Duval and NeSmith (1999) also reported that scarified seed germinated more uniformly than did nonscarified seeds. Nerson et al. (1985) found that lateral splitting of seeds did not improve germination in diploids, but increased in tetraploids. In our preliminary tests, nicking was effective in improving germination for triploid cultivars ASM 0121, ASM 1616, and

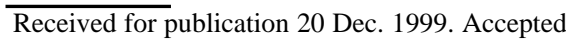
for publication 25 May 2000. The cost of publishing this paper was defrayed in part by the payment of page charges. Under postal regulations, this paper therefore must be hereby marked advertisement solely to indicate this fact.

'E-mail address: sgrange@ taexgw.tamu.edu

${ }^{2}$ To whom requests for reprints should be addressed.
} moisture levels. a mean $\pm \operatorname{SE}(\mathrm{n}=4)$.
ASM 1614 (American Sunmelon; Novartis Seeds, Boise, Idaho). Seeds for all these exinents were germinated in petri high medium moisture and nicking on seed germination is unknown. This experiment was conducted to: 1) examine the influence of low and high medium moisture on seed germination of triploid watermelon; and 2) determine if nicking enhances germination at these
One diploid cultivar, 'Charleston Gray', and three triploid cultivars, 'ASM0121', 'ASM 1616', and 'ASM 1614', were used. Seeds were nicked with a razor blade by cutting a 12-mm-diameter hole at the end of the seed opposite the radicle without injuring the embryo. Four replications were used for each cultivar, with 25 seeds per replicate. Seeds were placed in 9-cm petri dishes with one layer of seed germination paper, which was moistened with either $5 \mathrm{~mL}$ of distilled water for the low moisture level (considered optimal) or 10 $\mathrm{mL}$ for the high moisture level. Seeds were incubated in darkness at a constant $25^{\circ} \mathrm{C}$ and germination was counted every $12 \mathrm{~h}$ for $7 \mathrm{~d}$. Seeds were considered germinated when the radicle protruded $2 \mathrm{~mm}$ from the seedcoat. Total seed weight and seed components were measured by randomly selecting 10 seeds from each cultivar. Each seed was cut longitudinally and placed under a $18 \times$ magnification stereo microscope. Thickness of the seedcoat and the distance between the edge of the cotyledons and innermost layer of the seedcoat was measured with an eyepiece micrometer. The embryo was then excised, the seedcoat weighed, and the weight of the embryonic axis calculated.

\section{Results and Discussion}

Germination of the diploid 'Charleston Gray' was not affected by moisture level or nicking (Fig. 1), averaging $92 \%$ to $95 \%$ over all treatments. All control (intact) triploids had lower germination percentages than did the diploids under optimal low moisture, averaging $80 \%$. However, germination of the triploids was severely reduced $(<15 \%)$ under high moisture conditions. At the optimal moisture level nicking appeared to improve germination of intact seeds of all triploids, but this increase was nonsignificant. However, nicking significantly increased germination to between $35 \%$ and $40 \%$ under high moisture conditions.

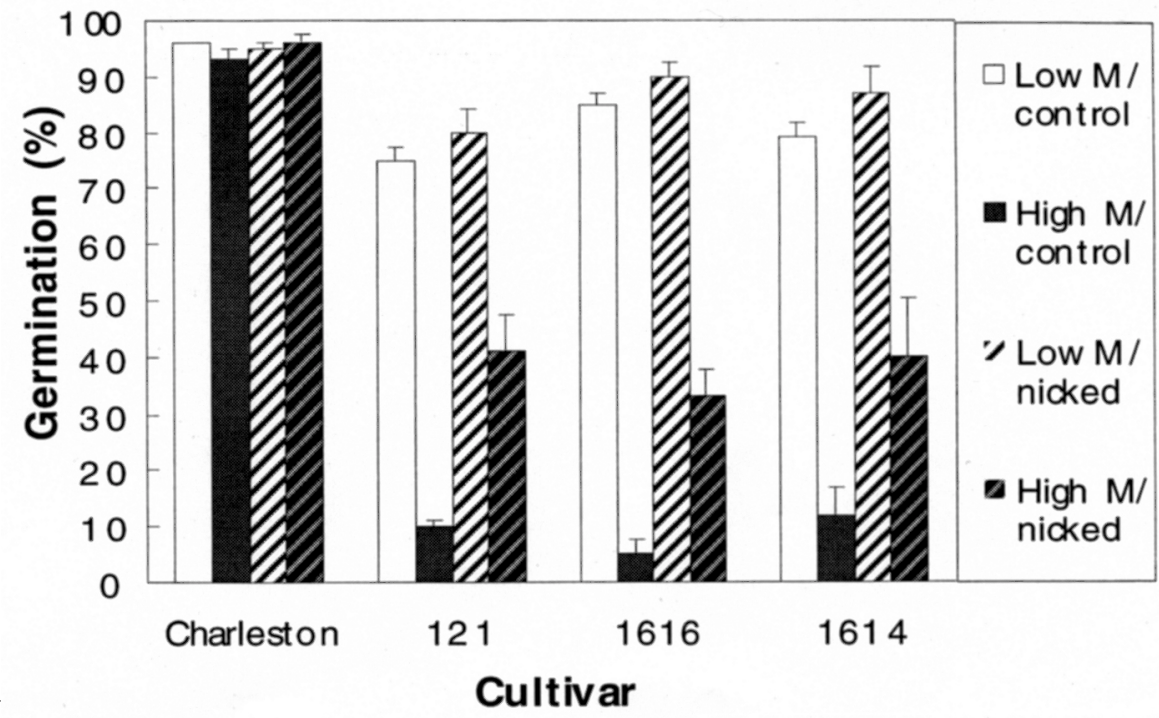

'ASM 1616', 'ASM 1614') in response to nicking and moisture (M) conditions. Each bar represents 
Table 1. Individual seed characteristics of one diploid and three triploid watermelon cultivars. Values are means $\pm \operatorname{SE}(n=10)$.

\begin{tabular}{|c|c|c|c|c|c|c|}
\hline \multirow[b]{2}{*}{ Cultivar } & \multicolumn{3}{|c|}{ Wt (mg) } & \multirow{2}{*}{$\begin{array}{c}\text { Seed length } \\
(\mathrm{mm})\end{array}$} & \multirow{2}{*}{$\begin{array}{l}\text { Coat thickness } \\
(\mathrm{mm})\end{array}$} & \multirow{2}{*}{$\begin{array}{l}\text { Air space } \\
(\mathrm{mm})\end{array}$} \\
\hline & Whole seed & Seedcoat & Embryo & & & \\
\hline Charleston Gray (2n) & $94.4 \pm 3.0$ & $48.6 \pm 2.1$ & $46.1 \pm 1.1$ & $12.1 \pm 0.2$ & $0.43 \pm 0.02$ & $0.07 \pm 0.02$ \\
\hline ASM O121 (3n) & $70.8 \pm 3.9$ & $41.0 \pm 1.3$ & $29.8 \pm 3.2$ & $9.7 \pm 0.1$ & $0.50 \pm 0.04$ & $1.10 \pm 0.36$ \\
\hline ASM $1614(3 n)$ & $70.4 \pm 2.3$ & $41.0 \pm 1.1$ & $29.3 \pm 1.5$ & $9.9 \pm 0.1$ & $0.46 \pm 0.02$ & $2.27 \pm 0.55$ \\
\hline ASM $1616(3 n)$ & $65.8 \pm 3.0$ & $37.0 \pm 1.5$ & $28.8 \pm 1.9$ & $9.5 \pm 0.1$ & $0.48 \pm 0.02$ & $0.89 \pm 0.34$ \\
\hline
\end{tabular}

These data confirm that seed germination is not inhibited by the seedcoat alone, as reported by Nerson et al. (1985). Triploid watermelon seed appears to be sensitive to water stress, possibly because of a combination of physiological and morphological defects. Kihara (1951) noted that triploid embryos, unlike diploids, do not completely fill the seed cavity, possibly because they are weak and poorly developed. In this experiment, triploid seeds were lighter and smaller, with a greater air space and generally thicker seedcoat, than the diploid 'Charleston Gray' (Table 1).
In triploids, the thicker seedcoat, combined with a large air space in the seed cavity, could restrict oxygen uptake under high moisture conditions by allowing water to collect and form a layer around the embryo. This would result in the embryo being in a water-saturated microenvironment, although the seed was exposed to air. In diploid watermelon seed, Botha et al. (1984) reported that oxygen uptake is reduced under conditions of water stress. The large air space in triploids also results in the embryo having to expand more before the radicle can emerge. The large variability in the air space could be related to the lack of germination and emergence uniformity under wet conditions.

\section{Literature Cited}

Botha, F.C., J.G.C. Small, and N. Grobbelaar. 1984. The effect of water stress on the respiration and some aspects of respiratory metabolism of Citrullus lanatus seeds. Seed Sci. and Technol. 12:585-595.

Duval, J.R. and D.S. NeSmith. 1999. Emergence of 'Genesis' triploid watermelon following mechanical scarification. J. Amer. Soc. Hort. Sci. 124:430432.

Duval, J.R. and D.S. NeSmith. 2000. Treatment with hydrogen peroxide and seedcoat removal or clipping improve germination of 'Genesis' triploid watermelon. HortScience 35:85-86.

Kihara, H. 1951. Triploid watermelons. Proc. Amer. Soc. Hort. Sci. 58:217-230.

Maynard, D. 1989. Triploid watermelon seed orientation affects seedcoat adherence on emerged cotyledons. HortScience 24:603-604.

Nerson, H., H.S. Paris, and Z. Karchi. 1985. Seed treatments for improved germination of tetraploid watermelon. HortScience 20:897-99. 